Karin Martensen

\title{
Der annotierte Klavierauszug - eine Quelle für die Interpretationsforschung?
}

\section{Einleitung}

Als Richard Strauss' Elektra am 24. März 1909 in Wien erstmals aufgeführt wurde, hatte Anna Bahr-Mildenburg (1872-1947) die Rolle der Klytämnestra übernommen. Mit ihrer Darstellung konnte sie, auch bei späteren Aufführungen in ganz Europa ${ }^{2}$ große Erfolge verbuchen. In einer Rezension von Richard Specht in der Zeitschrift „Die Musik“ hieß es etwa:

„Die Mildenburg ist als Klytämnestra von grauenvoller tragischer Gewalt, einem beklemmenden Phantom gleich, von bösen Träumen gejagt, von tückischer Angst geschüttelt; ihre Schritte, die wie unter blutiger Last taumeln, ihre tastenden Hände, die nicht fassen können, was sie greifen wollen, ihre schweren Lider, auf denen die Müdigkeiten eines verwüsteten, grausamen Lebens lagern - eine Gestalt, wie sie die Opernbühne vor dieser großen Künstlerin kaum geahnt hat. ${ }^{\text {“3 }}$

Die nachfolgenden Ausführungen haben nicht nur zum Ziel, die Künstlerin als Darstellerin der Klytämnestra zu würdigen, sondern sollen vor allem ihr Darstellungskonzept anhand ihres mit handschriftlichen Eintragungen versehenen Klavierauszuges zur Elektra beleuchten. Gefragt werden soll einerseits, wie dieses in den zeitgenössischen Diskursen zur Bühnendarstellung positioniert war. Andererseits geht es um die Frage, ob mit diesem Konzept eine in der Partitur möglicherweise immanente gestische Interpretation der Figur oder jedenfalls die Medialität von Körper und Stimme sichtbar und einer wissenschaftlichen Betrachtung zugänglich gemacht werden kann.

Bereits vor ihrem ersten Auftreten als Klytämnestra hatte sich Anna Bahr-Mildenburg Ruhm als hochdramatischer Sopran erworben. Zu Beginn der Spielzeit 1895, also mit knapp 23 Jahren, war die junge Sängerin an das Hamburger Stadttheater (heutige Staatsoper) verpflichtet worden. Hier debütierte sie unter Leitung von Gustav Mahler mit großem Erfolg im September 1895 als Brünnhilde in Wagners Walküre. Bereits 1897 gastierte sie zum ersten Mal als Kundry in Bayreuth. Ein Jahr später wurde sie auf Vermittlung Mahlers als Ensemblemitglied an die Wiener Hofoper verpflichtet. Dort trat sie als Ortrud in Wagners Lohengrin erstmals auf und feierte ihr Rollendebüt als Isolde in dessen Tristan und Isolde am

1 Dieser Aufsatz stellt eine überarbeitete Fassung meines Vortrags vom 8. Mai 2015 beim Symposium „Interpretationsforschung - Künstlerischer Vortrag im Spiegel historischer Texte und Tonaufnahmen“ an der Hochschule der Künste Bern dar. Für das Korrekturlesen und für hilfreiche Hinweise bedanke ich mich bei Beatrix Obal, Berlin.

2 Die Londoner Premiere der Elektra fand mit Anna Bahr-Mildenburg als Klytämnestra am 19. Februar 1910 im Royal Opera House Covent Garden statt. Über den enormen Erfolg berichtete die Wiener "Neue Freie Presse" (mit Bezug auf die Berichterstattung in englischen Zeitungen) gleich zwei Mal in Superlativen: „das größte musikalische Ereignis Englands seit vielen Jahren“ (NFP, 20.2.1910, S. 15); „ein Theaterereignis ersten Ranges“, es sei „noch niemals ein so schrankenloser Enthusiasmus" erlebt worden (NFP, 24.2.1910, S. 10). Die Sängerin selbst berichtet über dieses Ereignis in ihren Erinnerungen („Londoner Erinnerungen“, in: Anna Bahr-Mildenburg, Erinnerungen, Wien 1921, S. 159-168) sowie in der NFP vom 16.4.1911, S. 17f.

3 Richard Specht, in: Die Musik, 2. Aprilheft, 1908/09, S. 112. 
13. Februar 1900. Große Anerkennung erhielt sie auch für andere Rollen, etwa die Elisabeth in Tannhäuser und die Brünnhilde in der Götterdämmerung sowie für ihre Donna Anna in Mozarts Don Giovanni, in der sie zur Größe einer „singenden Tragödin“ vom Rang einer Eleonora Duse aufstieg, wie ihr Ehemann Hermann Bahr enthusiastisch urteilte. Ebenso erfolgreich fielen ihre Debüts in der Titelrolle von Verdis Aida sowie als Senta in Wagners Fliegender Holländer aus. 1901, also nach dreijähriger Zugehörigkeit zur Hofoper, wurde sie dort zur k.u.k. Kammersängerin ernannt. 1905 gastierte Anna Bahr-Mildenburg als Isolde am Deutschen Landestheater in Prag sowie im Juni 1906 in London; mit dieser Aufführung hatte sie so großen Erfolg, dass man ihr einen Gastspielvertrag an der Metropolitan Opera in New York anbot, den sie jedoch ablehnte. Künstlerische Erfolge in der Spielzeit 1904/05 waren die Mitwirkung der Sängerin in Beethovens Fidelio sowie in der Neuinszenierung des Ring des Nibelungen, die Gustav Mahler in Zusammenarbeit mit Alfred Roller vorbereitet hatte. Nach dem Weggang Mahlers von der Wiener Bühne Ende 1907 gehörte - wie schon erwähnt - die Darstellung der Klytämnestra zu Anna Bahr-Mildenburgs herausragendsten künstlerischen Erfolgen. 1916 verabschiedete sie sich mit dieser Rolle von der Bühne der Wiener Hofoper. Nach dem Ende des Ersten Weltkrieges war sie nur noch sporadisch Gast an der Staatsoper (wie die Hofoper seitdem hieß), dann vor allem in der Rolle der Klytämnestra. Mit dieser Partie nahm sie 1931 bei den Augsburger Opernfestspielen ihren endgültigen Abschied vom öffentlichen Bühnenleben. ${ }^{4}$

Auf der Suche nach einem Darstellungskonzept Bahr-Mildenburgs für die Klytämnestra wird man zunächst enttäuscht. Es gibt kaum direkte Äußerungen der Künstlerin darüber, welche Intentionen sie in Bezug auf diese Figur verfolgte, was sie also mit Hilfe von Stimme, Kostüm und Gestik auf der Bühne über die Klytämnestra ausdrücken wollte. Einer kurzen Tagebuchnotiz ist lediglich zu entnehmen, dass es ihr um die Darstellung eines ,gepeinigten, gefolterten Weibes" ging. ${ }^{5}$ Eine umso deutlichere Sprache scheint der von ihr mit handschriftlichen Eintragungen versehene Klavierauszug der Elektra zu sprechen, der sich heute in der Österreichischen Nationalbibliothek Wien befindet. ${ }^{6}$ Diesen hat Bahr-Mildenburg so überreich mit emotionalen Anweisungen und Bewegungsvorschriften für die Klytämnestra versehen, dass daraus ein Charakterbild dieser Figur entsteht.

Sehr bezeichnend für die Darstellungsideale der Künstlerin und ihre Ästhetik - und darauf werde ich im Folgenden noch weiter eingehen - ist eine weitere Tagebuchnotiz aus dem Jahr 1928, die wie folgt lautet:

„[...] denn alles, alles vermag mein Genie zu erfassen, zu begreifen, zu verkörpern. Tod und Leben, Liebe und Hass, Lachen und Weinen - eine ungeheure Scala mit tausend und tausend Zwischentönen

4 Vgl. zu diesen biographischen Angaben Franz Willnauer, Gustav Mabler: „Mein lieber Trotzkopf, meine süße Mohnblume". Briefe an Anna von Mildenburg, Wien 2006, insbesondere S. 419ff.

5 Mit Ausnahme der Jahre 1890 bis einschließlich 1903, die nach dem jetzigen Stand der Forschung verloren sind, befinden sich die Tagebücher bei ihrem Nachlass im Theatermuseum in Wien (Kartons 78 bis 82, Sign. A-BaM). In diesen Tagebüchern, die Bahr-Mildenburg sämtlich handschriftlich geführt hat (zum Teil in Form einer Vielzahl dicht beschriebener Schreibhefte im Format DIN-A5 - oft mehrere Hefte pro Jahr -, zum Teil stichwortartig in Taschenkalendern), schildert sie nicht nur Begebenheiten und Begegnungen ihres Privatlebens, sondern beobachtet auch genau die Ereignisse, die sich in ihrer Umgebung abspielten. Ferner nimmt sie ausführlich Stellung zu Erlebnissen ihrer Berufsbiographie. Ein weiteres Tagebuch Bahr-Mildenburgs aus dem Jahr 1911 befindet sich (ohne Sign.) im Archiv des Forschungsinstituts für Musiktheater (fimt) in Schloss Thurnau.

6 Signatur M.S. 67375; eine Kopie der Szenen, in denen die Klytämnestra auftritt, wurde mir freundlicherweise zur Verfügung gestellt. 
spielt der Genius in mir. Töne, die aus den letzten verborgensten Winkeln der menschlichen Seele erklingen, höre ich und lasse sie wiedererklingen, zur Seligkeit, zur Angst, zum Entsetzen, zum Schauer, zur lichten Freude der Menschen, und ich weine und lache und sie weinen und lachen mit mir und vergehen mit mir zu Schauern der Liebe und Hingabe, alles alles mache ich durch, und sie mit mir. ${ }^{\text {"7 }}$

Auch wenn es sich hierbei sicherlich in hohem Maße um Selbststilisierung handelt, so steckt in diesem Zitat meines Erachtens ein starkes Movens auch für ihre Klytämnestra-Darstellung. - Bevor ich hierauf und auf den Klavierauszug näher eingehe, seien kurz die Umstände der Wiener Elektra-Aufführung skizziert.

\section{Elektra in Wien}

Strauss und sein Librettist Hugo von Hofmannsthal hatten im Vorfeld aller Aufführungen (also auch der Uraufführung im Januar 1909 in Dresden und einer Folgeaufführung im Februar 1909 in Berlin) dafür gesorgt, dass ein Klavierauszug erstellt wurde, der den jeweiligen Sängerinnen und Sängern zur Vorbereitung zur Verfügung stand, wie dies allgemein üblich war. Allerdings waren Darstellungs- und Bewegungsanweisungen in Partitur und Klavierauszug nur rudimentär vorhanden. Das Autorenteam ging offenbar davon aus, dass dies für eine Erarbeitung der Figuren ausreichend sei und getrost in die Hände der jeweils verpflichteten Sänger und Sängerinnen gelegt werden könne. Hierfür konnten sie sich auf eine seit langer Zeit bestehende Tradition an den europäischen Opernbühnen berufen, wonach angehende Sängerinnen und Sänger eine umfassende Ausbildung in der vokalen Gestaltungspraxis erhielten. Diese war auch Grundlage für die Bühnendarstellung und ließ den Sängern einen großen Gestaltungsspielraum für die Interpretation der Figuren, die sie nach den erlernten Regeln, aber auch nach ihren individuellen Fähigkeiten auszufüllen hatten. ${ }^{8}$ Diese Ausbildungspraxis blieb bis weit in die erste Hälfte des 20. Jahrhunderts hinein üblich und gehörte daher in dieser Zeit zum Kernbestand des Gesangsunterrichts. ${ }^{9}$ Auf diese Weise wurden die Darsteller in die Lage versetzt, hinsichtlich der Interpretation einer Opernfigur auch die Verantwortung für deren Umsetzung zu übernehmen. ${ }^{10}$

Dies bedeutete freilich, dass die Sängerinnen und Sänger für die Erarbeitung einer Opernrolle vollkommen auf sich selbst angewiesen waren. Die (später absolut übliche und

7 Quelle: Nachlass Anna Bahr-Mildenburg im Theatermuseum Wien, Tagebuch 1928, Karton 80.

8 Wie die Traditionslinien der Gesangsausbildung verliefen, die auf eine Tätigkeit als Opernsänger bzw. -sängerin vorbereiten sollte, ist freilich in vielen Einzelheiten noch nicht erforscht. Vgl. zu diesem Thema z. B. Susan Rutherford, The Prima Donna and Opera, 1815-1930, Cambridge 2006; Dörte Schmidt, „Die Diva als Interpretin oder Warum Sophie Arnould das ,Kleid' nicht wollte, das Gluck ihr anbot“, in: „Per ben vestir la virtuosa“. Die Oper des 18. und frühen 19. Jahrhunderts im Spannungsfeld zwischen Komponisten und Sängern, hrsg. von Daniel Brandenburg und Thomas Seedorf (= Forum Musikwissenschaft, Bd. 6), Schliengen 2011, S. 113-129; Rebecca Grotjahn, Dörte Schmidt, Thomas Seedorf (Hrsg.), Diva - Die Inszenierung der übermenschlichen Frau. Interdisziplinäre Untersuchungen zu einem kulturellen Phänomen des 19. und 20. Jahrhunderts, Schliengen 2011; Rebecca Grotjahn, „Stimmbesitzer und Sängerdarsteller. Die Inszenierung des Singens auf der Musiktheater-Bühne in den ersten Jahrzehnten des 20. Jahrhunderts", in: Frankfurter Zeitschrift für Musikwissenschaft 14, 2011, S. 1-25; Thomas Seedorf, Art. „Singen“, in: MGG2, Sachteil 8, Sp. 1427ff., bes. Sp. 1442ff.; Thomas Seedorf (Hrsg.), Gesang (= MGG prisma), Kassel u. a. 2001; Mary Simonson, „Screening the Diva“, in: The Arts of the Prima Donna in the Long Nineteenth Century, hrsg. von Rachel Cowgill und Hilary Poriss, Oxford 2012, S. 83-100.

9 Grotjahn, „Stimmbesitzer und Sängerdarsteller“, S. 12.

10 Vgl. ebd., S. 3ff., bes. S. 9ff. 
unverzichtbare) Unterstützung eines Regisseurs konnten sie nur selten in Anspruch nehmen. Meist kamen sie mit Regisseuren erst in Kontakt, wenn sie sich nach Abschluss ihrer Ausbildung im Engagement auf einer Bühne befanden. ${ }^{11}$ Zudem entwickelte sich dieser Berufszweig erst mit Beginn des 20. Jahrhunderts zur künstlerisch inspirierenden und ordnenden Instanz. Im Vergleich zu Frankreich, wo die lyrische und dramatische Ausbildung der Opernsänger und -sängerinnen von jeher als „zwei Seiten derselben Medaille“12 verstanden wurde, vollzogen sich diese Erneuerungen im deutschsprachigen Raum deutlich später; hier genoss der Darsteller gegenüber dem Regisseur, wie Martin Knust schreibt, „noch recht lange eine ziemlich große Autonomie“. ${ }^{13}$ Anders formuliert: Es gab kein zentrales Regiekonzept, dass über die Ausfüllung der Rollen oder über Mimik und Gestik der Darsteller gewacht hätte. Vielmehr bestimmten die Akteurinnen und Akteure eigenständig, wie sie auf der Bühne agierten, und waren dabei nur vom (Noten-)Text, vom Standort der Requisiten und den Handlungen der Mitspieler abhängig. ${ }^{14}$

Das Beispiel Elektra zeigt, dass es schon kurz nach der Jahrhundertwende mit einer solchen Vorbereitung einer Rolle bzw. einer Aufführung durch die Darstellerinnen und Darsteller, die auf dem Klavierauszug als zentralem musikalischem Hilfsmittel beruhte, nicht mehr getan war. Was Strauss von seinen Sängern erwartete, geht aus einem Brief an Hofmannsthal vom 4. Mai 1909 hervor, den er diesem über die Fertigstellung des Rosenkavalier schrieb: „[...] Alle Figuren sind famos, scharf gezeichnet, brauche leider wieder sehr gute Schauspieler, mit den gewöhnlichen Opernsängern geht's schon wieder nicht. [...]“ - „Schon wieder nicht“, das bezog sich auf die Elektra. Auch hier also, so wollte Strauss sagen, war es seiner Ansicht nach nicht ausreichend, wenn die Ausführenden lediglich über gute gesangliche Fähigkeiten verfügten. Vielmehr hielt er es für erforderlich, dass die Sängerinnen und Sänger ebenso über hervorragende darstellerische Fähigkeiten verfügen müssten. Daher kamen seiner Ansicht nach „,gewöhnliche Opernsänger“ für die Ausführung der Elektra nicht in Frage. Strauss nahm damit Bezug auf eine neue Darstellungsästhetik, die sich seit der Jahrhundertwende auf den europäischen Bühnen mehr und mehr durchzusetzen begann. Dazu gehörte, dass Sänger und Sängerinnen den Charakter der darzustellenden Person auch durch Gestik ausdrücken sollten. Dies war der Fall, weil der leiblich-lebendigen Menschendarstellung auf der Bühne jetzt mehr und mehr Gewicht zukam, die auch eine veränderte Haltung zur Körperlichkeit des Darstellers bzw. Sängers nach sich zog. Dass es hier zu Modifikationen kam, hatte mit Veränderungen im ästhetischen Selbstverständnis der Sängerinnen und Sänger auf der Opernbühne zu tun und ebenso mit Veränderungen im Ausbildungssystem, die sich im Vergleich zu Frankreich - in Deutschland nur sehr langsam durchsetzten. ${ }^{15}$

11 Dies berichtet etwa die Sängerin Frida Leider (1888-1975), die später besonders für ihre darstellerischen Leistungen gerühmt wurde. Sie studierte privat Gesang, während ihre dramatische Ausbildung auf das Üben vor dem Spiegel beschränkt blieb (vgl. Leider, Das war mein Teil, Berlin 1959, S. 30).

12 So beschreibt es etwa Laura Moeckli in ihrem Aufsatz „Singers as actors on the Paris Grand Opéra stage“, in: Sänger als Schauspieler. Zur Opernpraxis des 19. Jahrhunderts in Text, Bild und Musik, hrsg. von Anette Schaffer et al. (= Musikforschung der Hochschule der Künste Bern, hrsg. von Martin Skamletz, Band 5), Schliengen 2014, S. 11-40 (Zitat S. 14).

13 Martin Knust, „Die Bühnengestik im 19. Jahrhundert. Quellen und Ansätze einer szenisch-musikalischen Rekonstruktion“, in: Musiktheorie 26, H. 4, S. 325-344, hier S. 340. Als Beleg führt Knust u. a. die Schriften von Richard Wagner und Eduard Devrient an, die dort „beständig gegen das von ihnen so genannte schauspielerische ,Virtuosentum ' [gewettert]" hätten. - Vgl. zum Thema auch: Arne Langer, Der Regisseur und die Aufzeichnungspraxis der Opernregie im 19. Jahrhundert, Frankfurt 1997.

14 Vgl. Grotjahn, „Stimmbesitzer und Sängerdarsteller“, S. 9f.

15 Vgl. die in Fußnote 8 genannte Literatur. 
Der Klavierauszug der Elektra half den Sängern jedoch auch hinsichtlich der dramatischen Darstellung einer Figur wenig weiter; vielmehr musste diese mangels entsprechender Einzeichnungen ebenfalls selbständig einstudiert werden. Es verwundert daher nicht, dass Anna Bahr-Mildenburg die Figur der Klytämnestra so gestaltete, wie sie es selbst für richtig hielt. ${ }^{16}$ Handschriftliche Notizen der Künstlerin über diesen Prozess finden sich in ihrem Klavierauszug. Fügt man diese montageartig aneinander, entsteht das Bild der Klytämnestra, die zwischen Wut und Verzweiflung hin- und hergerissen ist. Den Satz „bin ich lebendigen Leibs wie ein wüstes Gefild“ etwa soll Klytämnestra „verzweifelt“ singen und dabei die Arme auseinanderbreiten „wie: seht mich an“. ${ }^{17}$ Im Anschluss an die Worte „und ich schlachte, schlachte, schlachte Opfer um Opfer“ soll Klytämnestra „verzweifelt stehen weil alles vergeblich“ und „stöhnen“. ${ }^{18}$ Dass diese Verzweiflung bei Klytämnestra geradezu albtraumhafte Züge angenommen hat, verdeutlicht die Anmerkung Bahr-Mildenburgs zu den Worten „[ich will nicht mehr hören:] das ist wahr und das ist Lüge“; dort heißt es im Klavierauszug: "verblödet nach beiden Seiten Hände fallen lassen"19 - wobei ich annehme, dass mit „verblödet" nicht „dumm“, sondern „irre“ also „geisteskrank“" gemeint ist.

Es stellt sich die Frage, auf welcher Grundlage Bahr-Mildenburg zu einer solchen Ausdeutung der Figur kam. War dies wohl allein der Text, den sie in ihrem Klavierauszug vorfand? Oder könnte man die Hypothese wagen, dass sie für ihre Interpretation der Klytämnestra - unabhängig vom Text - auch die harmonischen Kühnheiten der Partitur des Werkes herangezogen bzw. diese ausgedeutet hat?

Es ist in der Musikwissenschaft seit längerem bekannt und gut erforscht, ${ }^{20}$ dass in der Elektra statt einer äußeren Handlung die psychischen Befindlichkeiten der Personen im Zentrum einer inneren Handlung stehen, die die Musik mit „nervösen Contrapunkten“ (wie Strauss das Phänomen selbst bezeichnete ${ }^{21}$ ) abbildet. Zusätzlich stimulierten Strauss zentrale expressive Pantomimen (etwa Elektras Tanz am Schluss der Oper) zum Einsatz analoger musikalischer Mittel. Nicht zu Unrecht sprach Norman Del Mar hinsichtlich Elektra und Salome von „stage tone poems“. ${ }^{22}$ Auch im Lexikon der Oper heißt es über die Figurenpsychologie in der Elektra und deren musikalischer Umsetzung, dass Strauss der Oper damit „völlig neue Ausdrucksbereiche“ erschlossen habe. Als das vielleicht herausragendste Beispiel der in musikalisches Neuland vorstoßenden Personencharakterisierung wird die Schilderung von Klytämnestras Angstzuständen genannt. Die musikalische Faktur tendiert hier zur Bildung von Klangflächen, wobei separate, bereits in sich dissonierende Akkordschichten ohne

16 Wie sich die Künstlerin in dem oben nur kursorisch angerissenen ästhetischen Diskurs positionierte und wie sie praktisch arbeitete, habe ich in meiner Dissertation anhand ihrer Regiebücher zu Richard Wagners Ring des Nibelungen dargestellt (Karin Martensen, Die Frau führt Regie. Anna Bahr-Mildenburg als Regisseurin des Ring des Nibelungen. Mit einem Anhang: Regiebücher zu Walküre, Siegfried und Götterdämmerung [= Beiträge zur Kulturgeschichte der Musik, Bd. 7, hrsg. von Rebecca Grotjahn], München 2013).

17 Vgl. Klavierauszug Elektra, S. 62. Zitate Bahr-Mildenburgs aus dem Klavierauszug sind hier und im Folgenden kursiviert, um sie von anderen Zitaten deutlich zu unterscheiden.

18 Vgl. Klavierauszug Elektra, S. 70.

19 Vgl. Klavierauszug Elektra, S. 71.

20 Vgl. dazu beispielhaft die in Fußnote 23 genannte Literatur.

21 Vgl. Richard Strauss. Betrachtungen und Erinnerungen, hrsg. von Willi Schuh, Freiburg 1949, S. 182, zitiert nach Walter Werbeck, Artikel „Strauss, Richard (Georg)“, in MGG2, Personenteil 16, Sp. 55115 (hier Sp. 97).

22 Norman Del Mar, Richard Strauss. A Critical Commentary on His Life and Works, Bd. 1, Kap. 2, zitiert nach Werbeck, ebd., Sp. 98. 
harmonische Beziehung übereinandergeblendet und im weiteren Verlauf wie clusterartige Blöcke chromatisch gegeneinander verschoben werden. Kurz: Der Stil der Musik wird aus der dramatischen Aktion gewonnen; Chrysothemis' eingängige Dreiklangsharmonik steht genauso wie die harmonischen Kühnheiten der Klytämnestra-Musik im Dienst der Verdeutlichung des Dramas. ${ }^{23}$

In ihren Interpretationsnotizen im Elektra-Klavierauszug hat sich Anna Bahr-Mildenburg auch mit der psychischen Befindlichkeit der Klytämnestra beschäftigt. Besonders bemerkenswert ist die Musik- und Textausdeutung der Sängerin in der Szene zwischen Elektra und Klytämnestra, in der letztere von ihren furchtbaren Träumen erzählt: Bereits die erste Frage, die Klytämnestra an Elektra richtet („Weißt du kein Mittel gegen Träume“) ist nur vordergründig freundlich; die Musik mit ihren überaus vieldeutigen Akkorden (zwei Takte nach Ziffer 178) deutet hingegen an, dass es natürlich keine angenehmen Träume sein werden, von denen dann im Anschluss die Rede ist. Bahr-Mildenburg notiert zu diesen beiden Takten: „lächeln wollen, aber dabei schaudern“. ${ }^{24} \mathrm{Zu}$ den Worten Klytämnestras an Elektra „du könntest vieles sagen, was mir nützt“ hat die Sängerin sowohl das im Klavierauszug abgedruckte „espressivo“ mit Bleistift eingekreist als auch den Einsatz des ersten Horns mit einer Ziffer 1 markiert, mit dessen „befremdlichen“ Tönen die zuvor „rauschhafte" Musik abbricht. Ihre Anweisung an Klytämnestra zu diesen Worten lautet, dass sie „schläfrig und blöd" klingen müssten (wobei ich „blöd“ wiederum mit „wahnhaft-krank“ gleichsetze). ${ }^{25}$ Und auch in den Worten ,ich bin nicht einmal krank“ (in der die Geigen mit einer sfz-Anweisung quasi in die Tiefe abstürzen) hört die Künstlerin Ausbrüche des geistigen Wahns Klytämnestras: die Anweisung lautet: „blöd“ „furchtgepeinigt“. ${ }^{26}$ - Man könnte in allen diesen Fällen überlegen, dass Bahr-Mildenburg durch ihre genannten Anweisungen die skizzierten Spannungsverhältnisse zwischen Text und Musik gestisch sichtbar gemacht hat. Dagegen spricht aber bereits, dass zahlreiche andere Eintragungen der Künstlerin zur Klytämnestra eindeutig nicht auf die Musik, sondern nur auf den Text bezogen sind. Dies betrifft etwa ihren Eintrag zum Text „die mir das Blut aussaugen“; hier heißt es: „saugend im Ton“ ${ }^{27}$ Hier sei aber grundsätzlich die Frage gestellt, ob ein annotierter Klavierauszug überhaupt sichtbar machen kan n, was in der Musik eines Werkes möglicherweise „verborgen“ ist; oder anders: ob er ein „Text“ ist, der Musik „lesbar“ macht.

\section{Die Partitur als Regiebuch?}

Der außerordentliche Erfolg Anna Bahr-Mildenburgs, den sie mit ihrer Interpretation der Klytämnestra erzielte, ist unbestreitbar und ging in die Theatergeschichte ein. Dennoch bleibt die Frage: Hat die Künstlerin mit den vorstehend skizzierten Anweisungen die „Sprache der Musik" erfasst? Ist in ihren schriftlichen Interpretationsnotizen eine gestische Umsetzung des von Text und Musik Angedeuteten zu erblicken? - Hierfür ergeben sich meiner Ansicht nach letztlich keine Belege. Denn wäre dem so, müsste man wohl tatsächlich von

23 Lexikon der Oper, hrsg. von Elisabeth Schmierer, Band I, Laaber 2002, S. 445f. - Vgl. zu diesem Thema auch: Tethys Carpenter, „The musical language of Elektra“, in: Richard Strauss: Elektra, hrsg. von Derrick Puffett (= Cambridge Opera Handbooks), Cambridge 1989, S. 74-106; Carolyn Abbate, „Elektra’s voice: Music and language in Strauss's opera, in: ebd., S. 107-127.

24 Klavierauszug Elektra, S. 77.

25 Ebd., S. 80.

26 Ebd., S. 82.

27 Ebd., S. 70. 
der Sprachhaftigkeit der Musik ausgehen, wie sie sich in der Partitur bzw. im Klavierauszug findet. Es soll mit diesen Überlegungen nicht an die in der Musikwissenschaft seit langem geführte Diskussion über „Musik als Sprache“, „Musik als Text“,28 über die Zeichenhaftigkeit von Musik oder allgemein zum Werkbegriff ${ }^{29}$ angeknüpft werden. Es geht mir vielmehr um die Frage, ob Musik, wie sie in einer Partitur vorhanden ist, eine bestimmte gestische Interpretation quasi in sich tragen kann. Oder noch anders: Ist die Partitur ein Regiebuch?

Die komplizierten Fragestellungen, ja hitzigen Diskussionen zur Zeichenhaftigkeit von Musik und zur Semiotik können im Rahmen dieses Aufsatzes allenfalls angerissen werden. Erwähnt seien etwa die Ausführungen von Christian Kaden, der bestreitet, dass Musik ein Zeichensystem katexochen auspräge. ${ }^{30}$ Karlheinz Stierle legt in seinem Aufsatz „Der Text als Werk und als Vollzug“ dar, dass die Partitur nur das „Projekt eines Werks“ sein könne, „das sich als werdendes Werk erst in der Konkretheit seiner Einlösungen verwirklichen kann“. In diesem Sinne sei „das musikalische Werk nichts anderes als eine Abstraktionsklasse maßgeblicher Realisierungen “31. Martin Zenck hingegen meint, dass die Kategorie des Performativen vom Notat nicht zu trennen sei, sondern ihm eingeschrieben ist: „Der Notentext, die Musik, wird nicht erst durch den Vortrag und die Aufführung performativ.“ In der Partitur finde sich eine „strukturierende Vorordnung“ des klingenden Ereignisses, zu der Aspekte wie Korporalität, Energetik und Materialität gehören. In diesem Sinn seien Partituren „Körperschrift“. 32 Werden daher „Parameter des Vokalen [...] durch die Partitur formuliert", wie es Stephan Mösch beschreibt?33

Dem möchte ich widersprechen. Es ist sicher richtig, dass jeder Komponist andere Vorstellungen darüber hat, wie seine Partitur umgesetzt werden soll, und daher das ihm erforderlich Erscheinende mehr oder weniger detailliert dort notiert. Möglicherweise kann man sogar sagen, dass sich in manchen Kompositionen Vortrags- und Ausdruckshinweise in der

28 Vgl. etwa: Hermann Gottschewski, Die Interpretation als Kunstwerk, Laaber 1996; Karlheinz Stierle, „Der Text als Werk und als Vollzug", in: Musik als Text. Bericht über den Internationalen Kongress der Gesellschaft für Musikforschung Freiburg im Breisgau 1993. Band 1: Hauptreferate, Symposien, Kolloquien, hrsg. von Hermann Danuser und Tobias Plebuch, Kassel 1998, S. 8-15.

$29 \mathrm{Zu}$ der neueren Diskussion vgl. etwa Gerhard R. Koch, „Was sehen wir beim Hören, was hören wir beim Sehen? Das Musiktheater, ein unbekanntes Wesen - Wagner hat sein Verschwinden mitkonzipiert", in: Wagnerspectrum. Schwerpunkt - focusing on Regietheater, hrsg. von Udo Bermbach u. a., Würzburg 2005, S. 9-21; Egon Voss, „Werktreue und Partitur“, in: ebd., S. 55-64; Laurenz Lütteken, „Wider den Zeitgeist der Beliebigkeit. Ein Plädoyer für die Freiheit des Textes und die Grenzen der Interpretation", in: ebd., S. 23-28.

30 Christian Kaden, Art. „Zeichen“, in: MGG2, Sachteil 9, Sp. $2149 f f$.

31 Stierle, „Der Text als Werk und als Vollzug“, S. 12.

32 Diese Zitate finden sich in der Ankündigung der Vortragsreihe „Kompositorische Perspektiven des Vokalen von Monteverdi bis Rihm", die vom 13. Oktober 2014 bis 6. Juli 2015 an der Hochschule für Musik Karlsruhe stattfand und in der „Musikforschung“ wie vorstehend angeführt abgedruckt war (siehe http://www.musikforschung.de/index.php/de/aktuelles/mitteilungen/796-karlsruhe; 3.10.2014). Den eigentlichen Fundort für das genannte Zitat von Zenck konnte ich nicht eruieren. Diesen Ansatz vertritt er jedoch auch in seinem Aufsatz „Gestisches Tempo. Die Verkörperung der Zeit in der Musik - Grenzen des Körpers und seine Überschreitungen“, in: Verkörperung, hrsg. von Erika Fischer-Lichte u. a., Tübingen 2001, S. 345-368 sowie in dem Aufsatz „Vom Berühren der Klaviertasten und vom Berührtwerden von Musik“, in: Verkörperungen der Musik: interdisziplinäre Betrachtungen, hrsg. von Jörn Peter Hiekel und Wolfgang Lessing, Bielefeld 2014, S. 117-136, insbesondere im Einleitungskapitel „Das Anathema ,Musik und Körper ““.

$33 \mathrm{http} / /$ www.musikforschung.de/index.php/de/aktuelles/mitteilungen/796-karlsruhe; 3.10.2014. 
Kompositionsstruktur selbst verbergen. ${ }^{34}$ So ist es denkbar, dass sich etwa ein Textinhalt im Klang, sogar im Klang eines Gesangstons vermittelt, und nicht im deklamierenden Gestus. ${ }^{35}$ Insofern könnte eine Partitur tatsächlich Interpretationsanweisungen an den Sänger enthalten. Zudem ist Musik selbstverständlich in der Lage, Emotionen im Darsteller hervorzurufen und zu einer (gesanglichen und/oder gestischen) Umsetzung quasi aufzufordern. ${ }^{36}$ Aber welche Umsetzung dabei konkret geschieht oder geschehen soll, vermerkt die Partitur eben nicht und kann dies auch nicht vermerken.

Wilfried Gruhn etwa wies am Beispiel des ersten Teils der Introduktion des I. Akts von Mozarts Zauberflöte („Zu Hilfe, zu Hilfe ...") darauf hin, dass auch gestisches Verstehen nur eine Verstehensmöglichkeit bietet, die ein Sänger nicht zwangsläufig umsetzen muss. ${ }^{37}$ Daraus ergibt sich bereits, dass der Körper bzw. die „Geste des Komponisten“, die Zenck ebenfalls in der Partitur auffinden will ${ }^{38}$, für Sängerinnen und Sänger unüberprüfbar und damit irrelevant bleiben muss. Auch Zenck bleibt die Antwort auf die Frage schuldig, wie denn Interpret und Komponist „mit ihrer Körperlichkeit“, vermittelt durch die Notenschrift, miteinander kommunizieren könnten. ${ }^{39}$ Hier wird meines Erachtens ein Werkbegriff sichtbar, der nicht nur von einer vollständigen Notierbarkeit des vom Komponisten Gemeinten ausgeht, sondern auch die Begriffe „Komponist" und „Werk" vollkommen gleichsetzt. Es wird aber anhand des Elektra-Klavierauszugs zu zeigen sein, dass ein solcher Werkbegriff - der ohnehin in den letzten Jahren aus guten Gründen stark in die Kritik geraten ist ${ }^{40}$ - zu keiner Lösung in der Interpretationsforschung führen kann. Dies ist schon deshalb der Fall, weil die Vorschriften, die ein Komponist in seiner Partitur vermerkt, nicht verallgemeinert werden können: Was etwa

34 Stephan Mösch hat dies für Wagners Parsifal herausgearbeitet in Weihe, Werkstatt, Wirklichkeit. Wagners Parsifal in Bayreuth 1882-1933, Kassel 2009, S. 208ff.

35 Vgl. dazu ebd., S. 213.

36 Vgl. dazu etwa Robert S. Hatten, Interpreting musical gestures, topics, and tropes, Bloomington 2004; Anthony Gritten, Elaine King (Hrsg.), Music and gesture, Farnham 2006; Rolf I. Godøy, Marc Leman (Hrsg.), Musical gestures. Sound, movement, and meaning, New York/London 2010; Aniruddh D. Patel, Music, Language, and the Brain, Oxford/New York 2008.

37 Vgl. Wilfried Gruhn, Musikalische Gestik. Vom musikalischen Ausdruck zur Bewegungsforschung, Hildesheim 2014, S. $73 \mathrm{f}$.

$38 \mathrm{Vgl}$. Zenck, „Gestisches Tempo“, S. 348ff. Zenck hält die Arbeit am Instrument durch den Komponisten für eine entscheidende Voraussetzung für körperliches Komponieren (vgl. ebd.). Ob und inwieweit dies geschieht, dürfte von Komponist zu Komponist unterschiedlich sein und ist daher (insbesondere für bereits verstorbene Komponisten) unüberprüfbar. Die wissenschaftliche Verwertbarkeit dieser Kategorie ist daher meines Erachtens problematisch.

39 Ebd., S. 352f. - In seinem Aufsatz „Luigi Nono - Marina Abramovic. Eingeschriebene, bewegte und befreite Körper zwischen Aufführungspartitur, Live-Elektronik und freier Improvisation/Performance“ (in: Performance im medialen Wandel, hrsg. von Erika Fischer-Lichte, Paderborn 2006, S. 119-145) formuliert Zenck, dass es sich um einen „corporalen Subtext“ des Komponisten handele, der „vermöge einer performativen Einschreibung im Notentext“ vorhanden und „in der Aufführung in die Gegenwart zu ziehen" sei (ebd., S. 120). Er führt dies in Bezug auf Kompositionen von Nono und Ligeti sowie in Bezug auf Performances von Marina Abramovic aus, kann für die genannte Behauptung aber keine generelle Begründung geben, die sich auch auf andere Komponisten und/oder Interpreten beziehen ließe.

40 Vgl. dazu stellvertretend Martin Elste, „Von der Partiturwissenschaft zu einer Klangwissenschaft. Überlegungen zur Schallplattenforschung", in: Jahrbuch des Staatlichen Instituts für Musikforschung PreuBischer Kulturbesitz 1983/84, Kassel 1987, S. 115ff. Grundsätzliche Ausführungen zum Werkbegriff macht auch Thomas Seedorf im Artikel „Singen/Komponist und Sänger“, in: MGG2, Sachteil 8, Sp. $1435 \mathrm{ff}$. 
Richard Wagner für Rienzi notierte, kann nicht automatisch auch in der Götterdämmerung Geltung beanspruchen. Vielmehr handelt es sich um verschiedene Anwendungen derselben Interpretationstermini. Erst recht gelten Anweisungen eines Komponisten in einer Partitur nicht für Partituren anderer Komponisten. Zudem steht nicht in der Partitur, wie etwa Mozart ein „messa di voce“ aufgefasst haben wollte. Ausführungen hierzu könnten höchstens indirekt aus zeitgenössischen Texten entnommen werden, doch können auch diese keine Allgemeinverbindlichkeit beanspruchen, sondern sind selbst Ausdruck des Diskurses, in dem sie stehen und spiegeln daher die Haltung des jeweiligen Autors zu dem betreffenden Diskurs wider. ${ }^{41}$ Und schließlich zeigt sich gerade an dem Elektra-Klavierauszug, dass sich Interpretationsansätze dadurch entscheidend verändern können, wenn sich zwei unterschiedliche Sängerinnen dem Werk auf verschiedene Art und Weise nähern, wie nachfolgend noch weiter ausgeführt werden soll.

Es bleibt aber die Schwierigkeit bestehen, wie die Leiblichkeit des Darstellers schriftlich fixiert werden könnte, angesichts der Binsenweisheit, dass der Körper des Sängers bzw. der Sängerin für die angemessene Darstellung einer Figur auf der Bühne unbedingt erforderlich ist. Auch in der Musikwissenschaft ist unbestritten, dass keine Gestaltung, keine Musik, keine darstellende und keine bildende Kunst jenseits von Korporalität zu denken ist. Diese wird dementsprechend als Medium oder Instrument, als Produkt sowie als Produzent von Wirklichkeit erfasst. Korporalität als sozial und kulturhistorisch bedingtes Medium ${ }^{42}$ sowie als Produkt gesellschaftlicher Machtverhältnisse ${ }^{43}$ ist mittlerweile gut untersucht und auch die deutschsprachigen Kulturwissenschaften beschäftigen sich seit dem performative turn in den

41 Es würde den Rahmen dieses Aufsatzes bei weitem sprengen, wollte ich hierzu weitere Ausführungen machen. Hingewiesen sei daher nur auf den bereits um 1900 einsetzenden Natürlichkeitsdiskurs in der Gesangspädagogik (parallel dazu auch in der Instrumentalpädagogik), der sich gegen die von ihren Vertretern sogenannte „Technisierung" der Stimme (resp. des Gesangsunterrichts) wandte. Stattdessen plädierte man für einen möglichst „natürlichen“ Gebrauch der Singstimme, die „seelischer Ausdrucksfaktor eines lebenden Körpers" sein müsste (so etwa Michael Arnolds, Das bewußt technisch richtige Singen. Versuch einer körperlich ursächlichen Darstellung, Würzburg 1938, S. 5). Damit wird die Nutzung des Körpers als „Gesangsorgan“ und das Schlagwort der „Natürlichkeit“ in einen engen Zusammenhang gebracht, ja geradezu synonym verwendet. Ausführungen in gesangspädagogischen Schriften zur Natürlichkeit des Gesangs dürfen daher nicht ungeprüft für wahr gehalten, sondern müssen stets in Bezug auf den genannten Diskurs gelesen werden. - Vgl. zum Ganzen etwa Maren Möhring, Marmorleiber. Körperbildung in der deutschen Nacktkultur (1890 bis 1930), Köln 2004; Philipp Sarasin, Reizbare Maschinen: Eine Geschichte des Körpers 1765-1914. Frankfurt am Main 2001.

42 Vgl. dazu etwa Pierre Bourdieu, Die feinen Unterschiede. Kritik der gesellschaftlichen Urteilskraft, Frankfurt 1982 sowie Erika Fischer-Lichte, Semiotik des Theaters. Band III: Die Aufführung als Text, Tübingen ${ }^{4} 1999$ und dieselbe: Ästhetik des Performativen, Frankfurt 2004; Barbara Duden, „Vom „Ich' jenseits von Identität und Körper", in: Körper und Identität. Gesellschaft auf den Leib geschrieben, hrsg. von Elisabeth Rohr, Königstein 2004, S. 16-31; Kornelia Hauser, „Die Repräsentation des authentischen Körpers", in: Körperrepräsentationen. Die Ordnung des Sozialen und der Körper, hrsg. von Kornelia Hahn und Michael Meuser, Konstanz 2002, S. 279-301.

43 Vgl. etwa: Stuart Hall, Ideologie, Identität, Repräsentation. Ausgewählte Schriften, Bd. 4, hrsg. von Juha Koivisto u. a., Hamburg 1994; Bell Hooks, Black Looks. Popkultur-Medien - Rassismus, Berlin ${ }^{1}{ }^{1}$ 994; Louis Althusser, Ideologie und ideologische Staatsapparate, Hamburg 2010; John L. Austin, Zur Theorie der Sprechakte, Stuttgart 1972; Michel Foucault, Archäologie des Wissens, Frankfurt 1973; Ders., Die Ordnung des Diskurses, Frankfurt 1991; Uwe Wirth (Hrsg.), Performanz. Zwischen Sprachphilosophie und Kulturwissenschaft, Frankfurt 2002; Jean Baudrillard, Von der Verführung, München 1992; Karin Hausen, „Die Polarisierung der ,Geschlechtscharaktere. Eine Spiegelung der Dissoziation von Erwerbs- und Familienleben“, in: Sozialgeschichte der Familie in der Neuzeit Europas. Neue Forschungen, hrsg. von Werner Conze, Stuttgart 1976, S. 363-393. 
90er-Jahren mit Korporalität als Produzent von Wirklichkeit. ${ }^{44}$ Dieser performative Aspekt von Korporalität wird - auch in der Tanzwissenschaft ${ }^{45}$, der Literatur zur elektronischen Musik $^{46}$ bzw. der Popularmusik ${ }^{47}$, der Anthropologie ${ }^{48}$ und der Musikpädagogik ${ }^{49}$ - mit den Termini „Leib“ bzw. „Körper“ beschrieben. Ferner ist die Materialität von Stimme und Sprache seit einigen Jahren gut erforscht ${ }^{50}$ und es darf als anerkannt gelten, dass im mimischen, gestischen und körpersprachlichen Vollzug nicht nur die Medialität der Sprache greifbar wird, sondern - durch Analogisierung des Sprechens mit einem musikalischen Geschehen - auch eine solche der Singstimme. ${ }^{51}$ Auch in der Musikwissenschaft haben diese Überlegungen inzwischen starken Widerhall gefunden. ${ }^{52}$

44 Vgl. etwa: Judith Butler, Körper von Gewicht, Frankfurt ${ }^{1}$ 1997; dies., Hass spricht. Zur Politik des Performativen, Berlin 1998; Robert Gugutzer, Soziologie des Körpers, Bielefeld 2004; Markus Schroeter (Hrsg.), Soziologie des Körpers, Frankfurt ${ }^{1} 2005$.

45 Vgl. etwa: Thomas Betzwieser u. a. (Hrsg.), Tanz im Musiktheater, Würzburg 2009; Gabriele Brandstetter, Tanz-Lektüren. Körperbilder und Raumfiguren der Avantgarde, Frankfurt 1995.

46 Vgl. etwa: Meike Jansen, Gendertronics: Der Körper in der elektronischen Musik, Frankfurt 2005.

47 Vgl. etwa: Sabine Meine, Nina Noeske (Hrsg.), Musik und Popularität. Aspekte zu einer Kulturgeschichte zwischen 1500 und heute, Münster 2011; Peter Wicke: „,Move your body'. Über den Zusammenhang von Klang und Körper", in: Das Populäre in der Musik des 20. Jahrhunderts: Wesenszüge und Erscheinungsformen, hrsg. von Claudia Bullerjahn und Hans-Joachim Erwe, Hildesheim 2001, S. 61-81.

48 Vgl. zur Konzeptualisierung der Musik innerhalb einer Historischen Anthropologie insbesondere Max Peter Baumann, „Musik“, in: Vom Menschen. Handbuch Historische Anthropologie, hrsg. von Christoph Wulf, Weinheim 1997, S. 974-984.

49 Vgl. etwa: Anja Kraus (Hrsg.), Körperlichkeit in der Schule. Aktuelle Körperdiskurse und ihre Empirie I, Oberhausen 2008.

50 Vgl. Doris Kolesch, Sybille Krämer (Hrsg.), Stimme. Annäherung an ein Phänomen, Frankfurt 2006; Doris Kolesch, Jenny Schrödl (Hrsg.), Kunst-Stimmen. Auditive Inszenierungen zwischen Live-Performance und Aufzeichnung, Berlin 2004; Kolesch u. a. (Hrsg.), Stimm-Welten. Philosophische, medientheoretische und ästhetische Perspektiven, Bielefeld 2009; Brigitte Felderer, Phonorama. Eine Kulturgeschichte der Stimme als Medium, Berlin 2004; Friedrich Kittler, Thomas Macho, Sigrid Weigel (Hrsg.), Zwischen Rauschen und Offenbarung: zur Kultur- und Mediengeschichte der Stimme, Berlin ${ }^{2} 2008$.

51 Vgl. Sybille Krämer, „Sprache - Stimme - Schrift: Sieben Gedanken über Performativität als Medialität", in: Performanz. Zwischen Sprachphilosophie und Kulturwissenschaften, hrsg. von Uwe Wirth, Frankfurt 2002, S. 323ff.; Dieter Mersch, „Jenseits von Schrift. Die Performativität der Stimme“, in: Dialektik. Zeitschrift für Kulturphilosophie, 2002/2, S. 79ff.

52 Eine Aufzählung auch nur der wichtigsten Titel zu diesem Themenbereich geriete ins Uferlose; es seien daher beispielhaft genannt: Maren Lorenz, Leibhaftige Vergangenheit. Einführung in die Körpergeschichte, Tübingen 2000; Hartmut Böhme, Natur und Subjekt. Frankfurt/Main 1988; Philip Sarasin, Reizbare Maschinen; Daniel Siemens, „Von Marmorleibern und Maschinenmenschen. Neue Literatur zur Körpergeschichte in Deutschland zwischen 1900 und 1936“, in: Archiv für Sozialgeschichte 47, 2007, S. 639-682; Julia Reuter, Geschlecht und Körper. Studien zur Materialität und Inszenierung gesellschaftlicher Wirklichkeit, Bielefeld 2011; Anke Charton, prima donna, primo uomo, musico. Körper und Stimme: Geschlechterbilder in der Oper, Leipzig 2012; Tim Becker, Plastizität und Bewegung. Körperlichkeit in der Musik und im Musikdenken des frühen 20. Jahrhunderts, Berlin 2005; Hans-Peter Bayerdörfer (Hrsg.), Musiktheater als Herausforderung. Interdisziplinäre Facetten der Theater- und Musikwissenschaft, Tübingen 1999; Josef Früchtl, Jörg Zimmermann (Hrsg.), Ästhetik der Inszenierung, Frankfurt 2001; Hans-Peter Bayerdörfer (Hrsg.), Stimmen - Klänge - Töne. Synergien im szenischen Spiel, Tübingen 2002; Christa Brüstle, Albrecht Riethmüller (Hrsg.), Klang und Bewegung. Beiträge zu einer Grundkonstellation, Aachen 2004; Clemens Risi, Mozart-Musiktheater - Wege des Performativen, Winterthur 2006, S. 137-148; Erika Fischer-Lichte, Clemens Risi, Jens Roselt (Hrsg.), Kunst der Aufführung-Aufführung der Kunst, Berlin 2004; Anno Mungen, „Spiel und Theatralität. Zur Frage der Performanz in der Dialo- 
Ausnahmen von alledem scheinen auf den ersten Blick für die französische Opernpraxis zu gelten, für die nicht nur andere Modalitäten in der Ausbildung der Sängerinnen und Sänger galten, wie oben schon angedeutet, sondern auch andere Konventionen hinsichtlich der Umsetzung, die durch Bilder, schriftliche Zeugnisse und sogenannte „livrets du mise-en-scène“ bzw. (in Italien) „disposizione sceniche “53 übermittelt, von den Akteuren praktiziert ${ }^{54}$ und vom Publikum - bis in das 20. Jahrhundert hinein - verstanden wurden. ${ }^{55}$ Es ist allerdings die Frage, ob dies auch heute noch gilt, da die genannten gestischen Konventionen auf den Bühnen längst vergessen sind bzw. vom Publikum mutmaßlich als unmodern eingestuft würden. Bereits Marcel Mauss wies darauf hin, dass körperliche Präsentationen stets auf kulturelle Referenzsysteme des Körperwissens und von Körpertechniken angewiesen sind, um verstanden zu werden. Oder anders: „Es gibt keine Technik und keine Überlieferung, wenn es keine Tradition gibt." 56

Gestützt wird diese Annahme auch durch Ergebnisse der historischen Emotionsforschung. Diese hat in den vergangenen Jahren vielfach dokumentiert, dass nicht nur die Ausdrucksformen bestimmter Empfindungen wie Freude oder Trauer historischem Wandel

goper“, in: Oper im Aufbruch. Gattungskonzepte des deutschsprachigen Musiktheaters um 1800, hrsg. von Marcus Lippe, Kassel 2007, S. 93-107.

53 Es handelte sich dabei um „spezielle[] Druckerzeugnisse[] zur Inszenierungsreproduktion“, die keinen dramatischen Text enthielten und deren Gebrauch ausschließlich auf den Theaterpraktiker zielte. Aufgrund dieser Unterlagen konnten sich Bühnen außerhalb der französischen Hauptstadt ihre Inszenierungen erarbeiten (vgl. Langer, Der Regisseur, S. 198; dort findet sich auch das o.g. Zitat). Im Detail sehr unterschiedlich, enthielten die mise-en-scène Bühnenbildbeschreibungen, Angaben über Stellungen der Personen sowie deren Kostüme und Beschreibungen der einzelnen Szenen. Diese Praxis war in Frankreich und Italien (= disposizioni sceniche) bis nach 1900 üblich und wurde im unterhaltenden Musiktheater bzw. der Operette bis in die 1920er Jahre hinein gepflegt. Auch wenn es sich bei diesen Spezialpublikationen sicherlich um Paratexte zur Partitur handelte, blieb die Durchdringung der Rolle im Detail dennoch Aufgabe der DarstellerInnen. Für den Bereich der Oper hält Langer zudem fest, dass „von vielen Spitzenwerken der Opéra-Comique und noch mehr der Opéra keine derartigen Zeugnisse vorliegen." (ebd., S. 226) Im übrigen Europa konnten sich die mise-en-scène hingegen nicht durchsetzen (vgl. zum Ganzen Langer, ebd., S. 193-226). In Deutschland gab es diesbezüglich nur vereinzelte Ansätze, doch lag der Schwerpunkt hier „eher auf dem bühnenbildnerischen als auf dem gestischen Moment der Inszenierung“ (Knust, „Die Bühnengestik im 19. Jahrhundert“, S. 32). Einzig für die Werke Richard Wagners ist bei Vorhandensein von Aufführungsprotokollen Dritter und gedruckten Regieanweisungen „stellenweise ein dichtes Netz von dramatischen Vorgaben“ festzustellen (Knust, ebd., S. 330). Schließlich sei angemerkt, dass dezidierte Rollenstudien so gut wie überhaupt nicht veröffentlicht wurden; ich vermute daher, dass es sie nicht gab. Langer nennt als einziges Beispiel die Arbeit von Jurij von Arnold (vgl. Langer, Der Regisseur, S. 247f.). Eine ähnliche Arbeit von Hermann Starcke aus dem Jahr 1874 nennt Langer eine „Privatinitiative“, über deren Rezeption nichts bekannt sei (ebd., S. 252). Langer führt dies darauf zurück, dass sich „im deutschsprachigen Raum sowohl die Komponisten als auch die Verlage offenbar wenig für die Verbreitung von Inszenierungsmustern interessierten“ (ebd.).

54 Vgl. dazu: Anette Schaffer, „Der beredete Leib. Das Bild und die französische Schauspielpraxis des 19. Jahrhunderts“, in: Sänger als Schauspieler, S. 41-73.

55 Vgl. dazu Moeckli, „Singers as actors on the Paris Grand Opéra stage“, die auch zahlreiches Bildmaterial hinsichtlich der gestischen Umsetzung von Emotionen auf der Bühne anführt. Ausführlich wird die Thematik behandelt in: Manuela Jahrmärker, Comprendre par les yeux. Zur Werkkonzeption und Werkrezeption in der Epoche der Grand opéra, Laaber 2006, bes. S. 99-163.

56 Marcel Mauss, „Körperwissen“, in: Der sprechende Körper: Texte zur Theateranthropologie, Zürich 1997, S. 70-76 (Zitat S. 75). 
unterliegen, sondern auch die Empfindungen selbst. ${ }^{57}$ Aus dieser Perspektive, so heißt es im Forschungsbericht von Sarah Zalfen, ,ist das Verhältnis von Musik und Gefühl keine Universalie, sondern von historischen und soziokulturellen Faktoren abhängig ". 58 Verständlichkeit der dramatischen Umsetzung beruht daher auf der Verständlichkeit der zugrundeliegenden gestischen und mimischen Konventionen; es besteht „kein kausaler Nexus zwischen einem bestimmten Musikstück und einer spezifischen emotionalen Wirkung “. 59 Letztlich handelt es sich hier um ein Weiterdenken der Überlegungen von Jonathan Sterne, dem „Gründervater" der historischen Klangforschung, wonach Hören und Sehen nicht einfach biologisch verankerte kognitive Vermögen des Menschen sind, sondern historisch geformte Kulturtechniken, deren Bedeutung und Hierarchisierung wandelbar sind und die deshalb in dieser Wandelbarkeit untersucht werden müssen. ${ }^{60}$ - Folglich gilt: Geraten auf der Opernbühne Konventionen deshalb in Vergessenheit, weil der zugrundeliegende ästhetische und soziohistorische Kontext verschwunden ist, zeigt sich, dass die Partitur eines Werkes aus einer solchen Periode keine Sprache und keine Umsetzung in sich selbst aufbewahrt, die nachfolgende Generationen nur hervorholen müssten. Partituren sind auch in diesem Fall keine Regiebücher und können eine bestimmte Umsetzung nicht bindend vorschreiben. ${ }^{61}$

Zudem warnte auch schon die französische Schauspieltradition vor einem unreflektierten Umgang mit Vorgaben. Der Theatertheoretiker Aristippe etwa schrieb, dass man als Schauspieler selbst bestimmen müsse, welchen Charakter und welche Emotion man mit einer Rolle verbinde. Eine einfache Befolgung von Regeln und Konventionen führe zur Monotonie und stehe damit im Widerspruch zur Natur, da diese nie zweimal das Gleiche hervorbringe. ${ }^{62}$ - Auch in der Wiener respektive in der italienischen Oper war es bis etwa der Mitte des 19. Jahrhunderts üblich, dass sich Sänger und Schauspieler in der szenischen Darstellung grundsätzlich nicht unterschieden, zumal sie die gleiche Ausbildung erhielten. Bemerkenswert ist jedoch, dass die Wiener Lehrbücher der Schauspielkunst des

57 Vgl. hierzu etwa: Ute Frevert, „Was haben Gefühle in der Geschichte zu suchen?“, in: Geschichte und Gesellschaft 35 (2009), S. 183-208 sowie dies. et al., Gefühlswissen: Eine lexikalische Spurensuche in der Moderne, Frankfurt 2011 (jeweils zitiert nach: Sarah Zalfen, Gefühlsbildungen des Musik-Erlebens. Forschungsbericht 2013 - Max-Planck-Institut für Bildungsforschung; Quelle: http://www.mpg. de/6769466/MPIB_JB_2013?c=7291695\&force_lang=de, 26.5.2015)

58 Zalfen, ebd.

59 Ebd.

60 In seiner wegweisenden Untersuchung wendet sich Sterne gegen gängige wirkungsgeschichtliche Erzählungen, die die Erfindung akustischer Medien wie des Telefons oder des Phonographen zum Ausgangspunkt nehmen, um dann deren Auswirkungen auf Hörgewohnheiten und -praktiken zu beschreiben. Sterne dreht diese Argumentation um und geht davon aus, dass die akustischen Medien nur erfunden werden konnten, weil sich bereits vorher Veränderungen im Status und in der Art des Hörens vollzogen hatten (vgl. The Audible Past. Cultural Origins of Sound Reproduction, Durham/London 2003).

61 Nur am Rande sei angemerkt, dass diese Überlegungen meines Erachtens auch für reine Instrumentalmusik gelten müssen. Die Leiblichkeit des Interpreten ist Teil des Spielens und ebenso seine Emotionen. Ob und inwieweit diese beiden Aspekte jedoch im konkreten Spiel eine musikalisch-gestische Umsetzung erfahren, ist nicht nur von Interpret zu Interpret verschieden, sondern in ihrer Historizität wandelbar und daher veränderlich. Eine ganz bestimmte Interpretation bzw. Interpretationspraxis ist daher aus den Werken nicht ableitbar. Interpretationsforschung muss folglich auch hier berücksichtigen, dass Aufführungsgewohnheiten und -praxen stets der Veränderung unterliegen. Vgl. zum Ganzen etwa: Sven Oliver Müller, Das Publikum macht die Musik. Musikleben in Berlin, London und Wien im 19. Jahrhundert, Göttingen 2014.

62 Aristippe, Théorie de l'art du comédien, Paris 1826, S. 241 und S. 236, zitiert nach Schaffer, „Der beredete Leib“, S. 63f. 
19. Jahrhunderts nach den Feststellungen von Christine Pollerus nicht die Geste oder die Mimik in den Vordergrund stellten, sondern die Empfindung, die der Akteur bei seiner Bühnendarstellung haben müsse, da die dramatische Wahrheit ausschließlich in der Tiefe der menschlichen Seele zu finden sei. ${ }^{63}$ Dies unterstreicht meines Erachtens, dass zwischen den französischen und den übrigen europäischen Ausbildungs- und Darstellungstraditionen gravierende ästhetische Unterschiede bestanden und dass diese daher nicht in einen Topf geworfen werden dürfen.

Dies lässt sich auch im Detail mit Blick auf die Gesamtdisposition der Opern Giacomo Meyerbeers erhärten. Heinz Becker ${ }^{64}$ legte dar, dass Meyerbeer seine Werke vom Sängerischen her entwickelt habe. Daher sei bei ihm „das Spektrum des Ausdrucksgesangs [geweitet] und differenziert" und deshalb seien hier im Nebentext reiche Vortragsanweisungen für Sänger zu finden, die den stimmlichen Ausdruck „bis in die kleinste Reaktion hinein [...] differenziert und determiniert." 65 Vollkommen anders stellt sich die Situation aber bei der Elektra dar, wie oben gezeigt: Es gibt so gut wie keine Anweisungen für die Sänger, vielmehr müssen sich diese die stimmliche Umsetzung selbst erarbeiten. Dies galt noch mehr für die gestische Ausgestaltung einer Figur: Hier wollte man keine Interpretation sklavisch vorschreiben, sondern - wie es in der Elektra-Partitur sichtbar ist - auch dies den Intentionen und Fähigkeiten der Darsteller überlassen. Französische und nicht-französische Opern(praxis) miteinander vergleichen zu wollen, halte ich daher auch aus diesem Grund nicht für möglich.

Schließlich sei im Zusammenhang mit Richard Wagners Musikdramen darauf hingewiesen, dass der Komponist zwar einen engen Konnex zwischen gestischer und mimischer Gebärde herstellte ${ }^{66}$ und sich auf der Bühne Inszenierungskonventionen hinsichtlich der Umsetzung von Melodie und Rhythmus eines Werkes etablierten. In schriftlichen Stellungnahmen (etwa von Hans von Wolzogen, einem engen Mitarbeiter Wagners) wurde suggeriert, dass eindeutig die mimische Gebärde Vorrang vor der musikalischen habe. Stephan Mösch führt dagegen aus, dass es sich dabei zwar um einen Lieblingstopos der Wagnerliteratur gehandelt habe, aber völlig unklar blieb, durch welche Parameter der intermediale Zusammenhang zwischen diesen beiden Gebärden hergestellt werden sollte, was mit „musikalischer Gebärde“ überhaupt gemeint war und dass zwischen „Geste“ und „Gebärde“ kein großer Unterschied gemacht wurde. ${ }^{67}$ Was Wagner mit seinen Überlegungen bezweckte, beschreibt Mösch als den Versuch, „Körperbewegungen als gestische und proxemische Zeichen einzusetzen, nämlich kontextbezogen und intersubjektiv bedeutungsgenerierend." 68 So selbstverständlich diese Forderung erscheint, so schwierig war und ist sie zu realisieren, da Wagner mit und durch Musik nicht den realistischen Ablauf einer dramatischen Szene beschreiben

63 Christine Pollerus, „,Zeichen der innern Empfindung‘. Zur Gestik in der Wiener Oper 1800-1850“, in: Sänger als Schauspieler, S. 124-141, insbes. S. 130ff.

64 Heinz Becker, „Zwischen Oper und Drama. Zu Meyerbeers Konzeption der dramatischen Szene“, in: Wagnerliteratur - Wagnerforschung. Bericht über das Wagner-Symposium München 1983, hrsg. von Carl Dahlhaus und Egon Voss, Mainz 1985, S. 86-94.

65 Alle Zitate: Ebd., S. 91

66 In Wagners Schrift Über die Benennung „Musikdrama“ etwa heißt es, dass die Musik die „Mutter des Dramas" sei. Die Musik tönt, ,und was sie tönt, möget ihr dort auf der Bühne erschauen“; sie öffnet sich den Zuschauern „wie das szenische Gleichnis, wie die Mutter den Kindern die Mysterien der Religion durch die Erzählung der Legende vorführt“ (Richard Wagner, „Über die Benennung ,Musikdrama"“, in: ders., Sämtliche Schriften und Dichtungen. Volksausgabe, Bände 1-12 und 16, Leipzig o. J. [1911], hier Bd. 9, S. 305).

67 Mösch, Weihe, Werkstatt, Wirklichkeit, S. 243ff.

68 Ebd., S. 107. 
konnte (oder wollte). Weil er außerdem mit musikalischen Mitteln alles Szenisch-Gestische über jedes Gebärdenspiel hinaus mit Ausdruck erfüllt und erfühlbar gemacht habe, ist Mösch der Ansicht, dass daher auch dem brillantesten Sängerdarsteller Grenzen gesetzt seien, sobald dieser die kinetische Oberfläche der Musik als Regiebuch verstünde. ${ }^{69}$ Das Thema „Musik und Gestik bei Wagner" hat sich wegen dieser Unschärfen bereits früh zu einem Topos der Wagner-Literatur verfestigt, den so gut wie alle Exegeten in unterschiedlicher Ausprägung aufgegriffen haben. ${ }^{70}$ Bis heute gehört das Thema zu den schwierigsten, mit denen sich die Forschung beschäftigt. $^{71}$

Zuletzt sei angefügt, dass die gesangliche und gestisch-dramatische Ausgestaltung einer Partie - wie oben schon angedeutet - bis weit ins 20. Jahrhundert hinein den Sängerinnen und Sängern selbst überlassen war. Wie zahlreiche Zeugnisse belegen, wurde dies lange Zeit gar nicht als Mangel empfunden, sondern war Bühnenalltag. Auch wenn die dramatische Bühnendarstellung selbstverständlich keine Erfindung des 20. Jahrhunderts ist, so ist dennoch zu konstatieren, dass schon vor 1900 Sängerinnen und Sänger die Bühnen betraten, denen die Präsentation einer schönen Stimme nicht mehr genügte, sondern künstlerischdramatische Intentionen auf dem Podium umzusetzen wünschten. Doch eine neue Art der Gesangsausbildung, die sich hinsichtlich der dramatischen Arbeit nicht mehr primär an den Gepflogenheiten der Sprechbühne und damit ausschließlich an den dramatischen Möglichkeiten der Stimme orientierte, gab es eine lange Zeit hindurch nicht. Im Gegenteil wurde von zahlreichen Sängerinnen und Sängern kritisiert, dass die große Masse der Gesangslehrerinnen und -lehrer ihren Schülern aufgrund eigener Uninformiertheit eher schaden als nützen könnten. Dramatischer Unterricht war - bis in unsere Tage hinein - nicht Gegenstand der Gesangsausbildung, und zwar auch dann nicht, wenn er für die Oper qualifizieren sollte. Vielmehr mussten sich die Elevinnen und Eleven selbst entsprechend um „Nachhilfe“ bemühen. ${ }^{72}$ Doch auch Regisseure hatten es lange Zeit hindurch schwer, eine den neuen Anforderungen genügende Ausbildung durchzusetzen. Hans Pfitzner etwa scheiterte in Straßburg mit seinem Versuch, eine Opernschule einzurichten, in der die Sängerinnen und Sänger nicht nur Partien lernen, sondern zugleich Unterricht im Bühnenspiel erhalten sollten. ${ }^{73}$ Und

69 Vgl. ebd., S. 107. - Stefan Kunze bezeichnete es sogar als „abwegig“, Wagners Musik als komponierte Regieanweisung zu verstehen. Er fügte jedoch auch an, dass die Leugnung der szenischen Komponenten dieser Musik nicht weniger an den wesentlichen Qualitäten der Wagnerschen Konzeption vorbeiginge (siehe Kunze, „Dramatische Konzeption und Szenenbezug in Wagners Tannhäuser“, in: Wagnerliteratur - Wagnerforschung, S. 196-210, hier S. 198f).

70 Siehe hierzu etwa: Friedrich Nietzsche, „Der Fall Wagner“, in: Kritische Studienausgabe, Bd. 6, hrsg. von Giorgio Colli und Mazzino Montinar, München 1999, S. 30ff; Paul Bekker, Wagner. Das Leben im Werke, Stuttgart 1924, S. 7; Theodor W. Adorno, Versuch über Wagner. Berlin 1952, S. 28; Carl Dahlhaus, „Die Bedeutung des Gestischen in Wagners Musikdramen“, in: Richard Wagner - Texte zum Musiktheater, hrsg. von Hermann Danuser (= Gesammelte Schriften, Bd. 7), Laaber 2004, S. 337ff.

71 Vgl. Mösch, Weihe, Werkstatt, Wirklichkeit, S. 243. Vgl. zu diesem Thema etwa: Stefan Kunze, „Szenische Vision und musikalische Struktur in Wagners Musikdrama“, in: De Musica. Ausgewählte Aufsätze und Vorträge, hrsg. von Rudolf Bockholdt, Tutzing 1998, S. 441-451; Tobias Janz, Klangdramaturgie. Studien zur theatralen Orchesterkomposition in Wagners „Ring des Nibelungen“, Würzburg 2006, S. 183. Janz nennt ferner neuere Literatur, die sich dem Thema unter medientheoretischen bzw. Performanzaspekten nähert (vgl. Janz, ebd., S. 184).

72 Dies vermerkt etwa die Sängerin Frida Leider in ihrer Autobiographie (Das war mein Teil, S. 30ff.). Vgl. zum Ganzen etwa Rebecca Grotjahn, „Stimmbesitzer und Sängerdarsteller“. Mit dieser Thematik habe ich mich auch ausführlich in meiner Dissertation befasst, vgl. Die Frau führt Regie, S. 29ff.

73 Vgl. Jeroen van Gessel, Die Praxis der Oper. Das Straßburger Stadttheater 1886-1944, München 2014, S. 339ff. - Zwischen 1908 und 1919 lebte Pfitzner mit seiner Familie in Straßburg. Dort leitete er das 
noch 1928 bemängelte der Regisseur Lothar Wallerstein, dass die dramatische Ausbildung der Sänger „nach wie vor“ sträflich vernachlässigt werde. ${ }^{74}$ Daher forderte er, in das Gesangsstudium eine rhythmisch-gymnastische Ausbildung nach Jaques-Dalcroze einzuführen, in der sich die angehenden Sänger ein Repertoire von Gesten und Bewegungen erarbeiten sollten. ${ }^{75}$ Wie lange es dann tatsächlich noch dauerte, bis diese Forderungen umgesetzt wurden, ist auch daran zu erkennen, dass der dramatische Unterricht in die Gesangsausbildung an den Hochschulen erst vor etwa 40 Jahren Eingang gefunden hat. ${ }^{76}$ - Um abschließend auf die Ausgangsfrage zurückzukommen: Aufgrund ihrer (aus heutiger Sicht) mangelhaften Gesangsausbildung waren die Sängerinnen und Sänger bis ins 20. Jahrhundert hinein zu dramatischer Aktion nur mit starken Einschränkungen befähigt. Daher wären sie - selbst wenn sie in der Partitur ein Regiebuch vorgefunden hätten - gar nicht in der Lage gewesen, dies zu bemerken und umzusetzen.

Zusammengefasst lässt sich daher festhalten: Es ist und bleibt Aufgabe einzig des Darstellers, die linguistischen und die paralinguistischen Zeichen der Partitur in konkrete Aktion umzusetzen. „Körperschrift“ im Sinne von Regiebuch-Vorschriften gibt es meines Erachtens in keiner einzigen Partitur. - Zudem kann man aus einem annotierten Klavierauszug, wie wir ihn hier vorliegen haben, die Interpretationsabsicht desjenigen erkennen, der ihn verfasste; in diesem Fall also die Absicht Anna Bahr-Mildenburgs. Aber dies lässt keine Rückschlüsse auf die spätere Aufführungssituation zu und erst recht kann man aus einem solchen Klavierauszug nicht schließen, dass er die Interpretationsabsicht des Komponisten hörbar oder sichtbar machen könnte oder würde. Oder noch anders: es handelt sich bei dem hier vorliegenden annotierten Klavierauszug nicht um einen „Text“, sondern um einen Akt der Rezeption.

\section{Vergleich: Ernestine Schumann-Heink als Klytämnestra}

Ein starkes Indiz hierfür lässt sich auch im Vergleich des Mildenburg'schen Klavierauszugs mit dem ihrer Kollegin Ernestine Schumann-Heink (1861-1936) aufzeigen. Diese war zwischen 1883 und 1897 an der Hamburger Oper engagiert und lernte dort Anna Bahr-Mildenburg kennen, die - wie oben erwähnt - 1895 in das Hamburger Ensemble aufgenommen wurde. Mit Rollen wie George Bizets Carmen und der Ortrud in Wagners Lohengrin gelang Schumann-Heink in Hamburg der Durchbruch als bedeutende Opernsängerin. Mit BahrMildenburg war sie seit dieser Zeit befreundet; mit ihr verband sie zudem die gemeinsame Arbeit am Festspielhaus Bayreuth, die diese in ihren Erinnerungen beschrieb. ${ }^{77}$ Im Januar 1909 übernahm Ernestine Schumann-Heink in der Dresdner Uraufführung der Elektra un-

Städtische Konservatorium und die Sinfoniekonzerte der Straßburger Philharmoniker. 1910 übernahm er zugleich die musikalische Leitung der Straßburger Oper, wo er auch als Regisseur wirkte.

74 Lothar Wallerstein, „Der Opernsänger von heute und seine Schulung“, in: Musikblätter des Anbruch, 1928, S. 362 (zitiert nach: Grotjahn, „Stimmbesitzer und Sängerdarsteller“, S. 4).

75 Wallerstein, ebd. S. 360f. (zitiert nach Grotjahn, ebd.). - Émile Jaques-Dalcroze (1865-1950) gilt als der Begründer der rhythmisch-musikalischen Erziehung. Von Genf aus verbreitete sich die seit 1902 gemeinsam mit Nina Gorter entwickelte Methode, die Methode Jaques-Dalcroze (MJD), unter dem Begriff „Rhythmische Gymnastik“ nach Deutschland und Österreich. Etwa seit 1925 ist Rhythmik ein Studiengang an den Musikhochschulen Deutschlands.

76 Auskunft von Prof. Matthias Remus, Dozent für Opernregie an der Hochschule für Musik und Theater Hannover, im Gespräch mit der Verfasserin am 1. Dezember 2010.

77 Vgl. Bahr-Mildenburg, „Gruß an Ernestine Schumann-Heink“, in: Erinnerungen, S. 105-113, der mit der Anrede „Meine liebe Tini!“ beginnt. 
ter Ernst von Schuch die Rolle der Klytämnestra. Es handelt sich daher um eine Vorstellung, die nur zwei Monate vor der Wiener Aufführung mit Anna Bahr-Mildenburg in derselben Rolle stattfand.

Zwar versah auch Schumann-Heink ihren Klavierauszug der Elektra mit handschriftlichen Eintragungen zur Figur der Klytämnestra, doch beschränkte sie sich dabei auf solche, die die korrekte, ausdruckshafte Deklamation des Textes sicherstellen sollten. Daher finden sich in ihrem Auszug, der sich heute in der Claremont University in Kalifornien befindet, ${ }^{78}$ beinahe in jedem Takt Zählzeichen, ferner einige Wortunterstreichungen, Crescendogabeln und Atemzeichen. Gelegentliche wortsprachliche Eintragungen wie „aufpassen“ dienten lt. Stephan Lowell Moss, der seine Dissertation über diesen Klavierauszug verfasste, der Abstimmung zwischen Schumann-Heink und ihrer Klavierbegleiterin, mit der sie die Rolle einstudierte. ${ }^{79}$ Zugleich dürften sie der Künstlerin als Hilfestellung angesichts der schwierigen rhythmischen Verhältnisse in der Partie gedient haben. Eintragungen hinsichtlich der dramatischen Ausgestaltung der Figur gibt es jedoch nicht. Schumann-Heink konzentrierte sich vielmehr auf die Ausgestaltung des Textes und war dadurch bestrebt - so formuliert es zumindest Stephan Lowell Moss -, „to project the verbal content of the libretto clearly, and to carry the emotional horror and intensity to the audience." 80

Man wird aus diesem Vorgehen sicher nicht schließen dürfen, dass Ernestine SchumannHeink die dramatische Umsetzung der Klytämnestra gleichgültig war oder dass sie hierauf bei der praktischen Darstellung auf der Bühne überhaupt kein Augenmerk richtete. Doch kann man - mit Blick auf die Klavierauszüge - angesichts der vollkommen unterschiedlichen Herangehensweise an die Ausgestaltung der Figur der Klytämnestra durch die beiden Künstlerinnen festhalten, dass man auch schriftliche Zeugnisse immer nach ihrer Medialität befragen muss. Für die Bewertung der beiden Klavierauszüge sollte man also unbedingt die Umstände ihrer Entstehung beachten. Hier zeigt sich, dass die beiden Künstlerinnen in Bezug auf die Klytämnestra eine sehr unterschiedliche Rezeptionshaltung an den Tag legten: Während Schumann-Heink ihre Interpretation offenbar ausschließlich auf den Text stützte und Eintragungen hinsichtlich der dramatischen Umsetzung auf der Bühne nicht für erforderlich hielt, liegt auf den gestisch-mimischen Notizen gerade der Schwerpunkt der Einzeichnungen Anna Bahr-Mildenburgs. Hieraus lässt sich wiederum der Schluss ziehen, dass es sich bei den Zeichen des Elektra-Klavierauszuges nur eingeschränkt um Aufführungsvorschriften handelt: Weder aus dem Text noch aus den Noten gehen bindende oder beschreibende Vorschriften hinsichtlich der Umsetzung der Klytämnestra hervor.

Wenn also die Partitur keine verbindliche Quelle für die Bühnendarstellung ist, kann folglich über „richtig“ oder „falsch“ der einen oder der anderen Interpretation überhaupt nichts gesagt werden. Instruktiv sind diesbezüglich die Rezensionen zur Mildenburg'schen Interpretation der Klytämnestra in der zeitgenössischen Presse. Ganz überwiegend waren

78 Dies ist vermutlich dadurch zu erklären, dass Schumann-Heink seit 1908 amerikanische Staatsbürgerin war und später in Hollywood/USA verstarb. - Für den Hinweis auf den Klavierauszug und die Dissertation von Stephan Lowell Moss („Ernestine Schumann-Heink as Klytemnestra in the Premiere of Elektra: An Analysis of Annotations in Her Working Scores“, The Claremont Graduate School, 1989), die sich gleichfalls in der Bibliothek der Claremont University befindet, bedanke ich mich herzlich bei Herrn Dr. Alexander Erhardt, wiss. Mitarbeiter an der Richard Strauss Gesamtausgabe an der LMU München.

79 Vgl. etwa Klavierauszug Schumann-Heink, S. 67 zum Text „was ist wahr und was ist Lüge“. - Bei Anna Bahr-Mildenburg gibt es solche Eintragungen nicht.

80 Lowell Moss, „Ernestine Schumann-Heink“, S. 89. 
diese positiv, wie eingangs dieses Aufsatzes schon angedeutet. ${ }^{81}$ Doch gab es auch negative Einschätzungen:
„War dieses in Krämpfen sich windende weibliche Ungetüm, daß in seiner weiten, faltenreichen, gel- ben Tracht unwillkürlich den Gedanken an die unförmliche Kaiserin-Mutter von China wachruft und dessen unnatürliche Bewegungen alle Augenblicke den Eindruck machten, als ob es Lust habe, an den Wänden emporzuklettern, wirklich Klytämnestra? [...] Wir finden beispielsweise Fräulein von Mil- denburg in Rücksicht auf ihre haarsträubenden Gliederverrenkungen für reif zu einem Engagement als Schlangentänzerin in einem Varieté." ${ }^{82}$

Wichtig erscheint mir, dass angesichts dieser Rezension und auch angesichts der nicht überragenden Kritiken, die Ernestine Schumann-Heink für ihre Klytämnestra-Darstellung erhielt ${ }^{83}$, noch nicht einmal ein sicheres Urteil darüber erlaubt sein kann, ob Bahr-Mildenburgs (oder Schumann-Heinks) Interpretation der Klytämnestra werkangemessen war oder nicht. Vielmehr trifft es die Sache wohl am besten, wenn man sagt, dass es sich hierbei um ihre jeweils höchstpersönliche Interpretation der genannten Figur handelt. Folglich handelt es sich nicht um Aussagen darüber, wie „man“ die Klytämnestra interpretieren „muss“ oder „soll“, sondern um die persönliche Rollenauffassung der Künstlerinnen.

\section{Andere Grundlagen für die szenische Darstellung?}

Kann die Frage, auf welcher Grundlage Bahr-Mildenburg in ihrem annotierten Klavierauszug die gestische Darstellung der Klytämnestra festlegte, vielleicht auf andere Weise geklärt werden?

81 „Die Mildenburg ist als Klytämnestra von grauenvoller, tragischer Gewalt, einem beklemmenden Phantom gleich, von bösen Träumen gejagt, von tückischer Angst geschüttelt; ihre Schritte, die wie unter blutiger Last taumeln, ihre tastenden Hände, die nicht fassen können, was sie greifen wollen, ihre schweren Lider, auf denen die Müdigkeiten eines verwüsteten, grausamen Lebens lagern - eine Gestalt, wie sie die Opernbühne vor dieser großen Künstlerin kaum geahnt hat."

82 Hans Puchstein, in: Deutsches Volksblatt, Wien, 25. März 1909.

83 In der Rezension von Ferdinand A. Geißler über die Uraufführung heißt es, dass Annie Krull als Elektra „einen Triumph [errungen]“ habe, „der ihren Namen in die allererste Reihe rückt“. Über Margarete Siems als Chrysothemis und Schumann-Heink heißt es im nächsten Satz zurückhaltender, dass sie „hervorragende Leistungen" erzielt hätten. (Franzpeter Messmer (Hrsg.), Kritiken zu den Uraufführungen der Bühnenwerke von Richard Strauss (= Veröffentlichungen der Richard-Strauss-Gesellschaft München, hrsg. von Franz Trenner, Bd. 11), Pfaffenhofen 1989, S. 77). Es erscheint daher bezeichnend, dass der Kritiker August Spanuth in Bezug auf diese Aufführung monierte, der zu singende Text sei kaum zu verstehen gewesen - mit Ausnahme von Schumann-Heink. Sie ,hatte eine solch' konzentrierte Schärfe in der Aussprache, daß fast jede Silbe in’s Ohr fiel [...]." (ebd., S. 75). Schumann-Heink konnte ihre künstlerischen Intentionen in Bezug auf die korrekte, ausdruckshafte Deklamation des Textes (vgl. oben im Haupttext) daher anscheinend erfolgreich umsetzen. Strauss selbst hatte keine sonderlich hohe Meinung von Schumann-Heinks Leistung als Klytämnestra. In seinen Erinnerungen schreibt er, dass die einstige berühmte Wagner-Sängerin sich als ein „Fehlgriff“ herausgestellt habe: „Mit alten Stars ist für mich nichts zu machen, - damals ahnte mir schon selbst, wie grundlegend mein Gesangsstil sich selbst vom Wagnerschen unterscheidet." (beide Zitate in: Strauss, Betrachtungen und Erinnerungen, 1949, S. 188f.). Anna Bahr-Mildenburg erhielt Strauss' Skizzenbuch zur Elektra bekanntlich von diesem als Geschenk. Dort findet sich folgende Widmung für die Künstlerin: „Der genialen Darstellerin der Klytämnestra in Wien[,] Frl. von Mildenburg[,] zur freundlichen Erinnerung an ihren größten Bewunderer. Der dankbare Componist der Elektra. Dr. Richard Strauss, Garmisch, 7. Mai 1909“ (Quelle: Theatermuseum Wien, Sig.: HS_Vk904BaM). 
Zunächst ist hierfür natürlich das Libretto von Hugo von Hofmannsthal selbst zu nennen, das wiederum auf dessen gleichnamiger Adaption des Stoffes beruhte. Nicht unerwähnt bleiben soll in diesem Zusammenhang auch, dass die Elektra als Schauspiel 1903 von Max Reinhardt inszeniert worden war. Strauss und Hofmannsthal kannten und bewunderten diese Inszenierung ${ }^{84}$; sie bzw. der Schauspieltext sind als Bezugsrahmen für das später entstandene Musikdrama mitzudenken.

Ob Anna Bahr-Mildenburg diese Inszenierung ebenfalls bekannt war, muss offen bleiben. In ihren Tagebüchern macht sie diesbezüglich keine Ausführungen. Die Wichtigkeit jedoch, die sie dem Text und seiner gestisch-dramatischen Umsetzung zumaß, ist bereits daraus zu erkennen, dass die Künstlerin in verschiedenen Aufsätzen zwar angab, für ihre Bühnendarstellung stets Musik und Text zur Grundlage ihrer künstlerischen Arbeit zu nehmen. In einem Aufsatz von ihr heißt es sogar, dass die Musik „klar und laut“ eine realistische Darstellung von Bühnenvorgängen „fordere“ ${ }^{85}$, also eine Sprachhaftigkeit besitze. In meiner Dissertation über die Ring-Inszenierung Bahr-Mildenburgs 1922 in München konnte ich jedoch zeigen, dass sie für ihre Darstellung der Brünnhilde, für die sie für alle drei Werkteile des Ring jeweils ausführliche Regiebücher verfasste, vor allem den subjektiv-emotionalen Gehalt nutzte, der dem Text/dem Libretto in ihren Augen innewohnte. Die Musik der drei Ring-Werkteile hingegen nutzte sie nur als „Anker“ bzw. sah sie als Impuls für die emotionale Haltung der Figuren an.

Dass es sich dabei nicht um einen Einzelfall handelt, sondern sich mit Bahr-Mildenburgs generellen ästhetischen Vorstellungen deckt, ergibt sich aus dem oben bereits erwähnten Zitat aus dem Tagebuch der Künstlerin aus dem Jahr 1928. ${ }^{86}$ Ganz grundsätzlich kann man daher sagen, dass sie ihre jeweilige Rolle aus ihrem persönlichen Empfinden entwickelte. Dieses wiederum kristallisierte sich aus den „Tönen“ heraus, die ihrer Ansicht nach „aus den letzten[,] verborgensten Winkeln der menschlichen Seele erklingen", die sie hören und verkörpern könne. Sie spürte also den Emotionen der von ihr verkörperten Figuren nach und ließ diese bei ihrer Bühnendarstellung ,wiedererklingen“ - und es sei angemerkt, dass Bahr-Mildenburg mit dieser Darstellungsweise, in der sie sich die Emotionen der Figuren ganz zu eigen machte, nicht nur den Nerv der Zeit traf, sondern ihr auch ihren europaweiten Ruhm als Sängerdarstellerin verdankte. $^{87}$

84 Ein Max Reinhardt zugedachtes Exemplar der Elektra versah Hofmannsthal mit folgender Widmung: „Max Reinhardt, dem wirklichen Regisseur [...]“ (zitiert nach: Konstanze Heininger, „Ein Traum von großer Magie“. Die Zusammenarbeit von Hugo von Hofmannsthal und Max Reinhardt, München 2015, S. 91, Auslassung wie dort).

85 Bahr-Mildenburg, „Moderne Inszenierung“, in: Neue Freie Presse, 25. Dezember 1926; Neue Freie Presse, 20. Februar 1927. Nachdruck in: Münchner Neueste Nachrichten, 26. Februar 1927 (Quelle: Theatermuseum Wien, Nachlass Anna Bahr-Mildenburg, Karton 70 [Eigenmanuskripte A bis K; Mappe "Inszenierung"]).

$86, \ldots[. .$.$] denn alles, alles vermag mein Genie zu erfassen, zu begreifen, zu verkörpern. Tod und Leben,$ Liebe und Hass, Lachen und Weinen - eine ungeheure Scala mit tausend und tausend Zwischentönen spielt der Genius in mir. Töne, die aus den letzten verborgensten Winkeln der menschlichen Seele erklingen, höre ich und lasse sie wiedererklingen, zur Seligkeit, zur Angst, zum Entsetzen, zum Schauer, zur lichten Freude der Menschen, und ich weine und lache und sie weinen und lachen mit mir und vergehen mit mir zu Schauern der Liebe und Hingabe, alles alles mache ich durch, und sie mit mir." (Tagebuch 1928)

87 Ausführlich habe ich dieses Thema in meiner Dissertation behandelt, siehe dort S. 140ff. und S. $250 \mathrm{ff}$. jeweils zum Stichwort „Weiblichkeit und Weiblichkeitskonstruktionen auf der Bühne“. 
Diese Überlegungen müssen meines Erachtens auch für Bahr-Mildenburgs Umsetzung der Elektra gelten: Auch hier scheint mir, dass Grundlage für die gestische Darstellung der Klytämnestra ebenfalls der Text ist sowie der emotionale Gehalt, den die Künstlerin ihm zumaß. Mit diesen Emotionen sind die Gesten und Gebärden verknüpft, die sie in ihrem Klavierauszug notierte. Letztlich ist dies als Versuch zu bewerten, eine intersubjektive und werkangemessene Gültigkeit der Interpretationsleistung herzustellen, der sich für die Sängerin vermutlich aus dem (unausgesprochenen) Erkennen entwickelte, dass es kein körpersprachliches Äquivalent zur musikalischen Charakterisierung gibt. Der Problematik des defizitären Sprachvermögens der kinetischen Zeichenebenen weicht Bahr-Mildenburg dadurch aus. Spezifika der Elektra, nämlich die Seelenlage der Klytämnestra und ihr Geisteszustand, wie sie sie aus dem Text herauslas und deutete, konnte sie auf diese Weise herausarbeiten.

Als weitere Grundlage für die Erarbeitung der Klytämnestra-Figur käme eine Zusammenarbeit oder jedenfalls eine Kontaktaufnahme Bahr-Mildenburgs mit dem Komponisten in Frage. Tatsächlich geht aus Briefen der Künstlerin an ihren Ehemann Hermann Bahr aus der Zeit vor der Wiener Erstaufführung der Elektra hervor, dass es bei ihr bis zur Generalprobe des Werkes erhebliche Unsicherheiten über die Richtigkeit ihrer Interpretation gab. Am 19. Februar 1909 etwa heißt es: „Wir arbeiten also mit Strauss! [...] Ob ihm meine Klytämnestra recht ist, hab ich eigentlich nicht herausgebracht. Fast hab ich das Gefühl, dass er mehr oder Anderes erwartet hat. Meine Leistung ist ja noch total unfertig und dann glaube ich, dass ich ihm zu wenig verblödet und krankhaft die Rolle auffasse. Wenn er mich auf der Bühne sehen würde - mit allem, was drum und dran ist, würde er mir ganz sicher recht geben und mich verstehen. Leider kommt er nicht zur Aufführung, weil er in Italien ist. "Und nach der öffentlichen Generalprobe der Elektra am 22. März, die für Bahr-Mildenburg ein großer Erfolg war, schreibt sie: „Strauss kommt und der soll einen vollen Eindruck haben, wenn ich die Klytämnestra darstelle. Ich gestalte sie mir innerlich immer mehr aus und die Figur klärt sich in mir immer mehr. ${ }^{\text {"88 }}$

Daher bemühte sich die Künstlerin, mit Strauss über die Umsetzung der Klytämnestra ins Gespräch zu kommen. Doch war dies ein vergebliches Unterfangen: Wie es wohl bei allen bis dahin entstandenen Werken seine Gewohnheit war, reiste Strauss nur für Uraufführungen im Vorfeld an, um mit den Sängern und Sängerinnen „auf Ausdruck“ zu studieren. ${ }^{89}$ Alles Übrige wollte er, wie dies bei anderen Einstudierungen auch geschah, Regisseur und Dirigent vor Ort überlassen. ${ }^{90}$ Auch der Librettist Hugo von Hofmannsthal war kein rechtzeitig erreichbarer Ansprechpartner für die Künstler: Zur Uraufführung der Elektra (die am 25. Januar 1909 stattfand) reiste er auf Strauss' Bitte Mitte Januar nach Dresden, um dort „nach dem Rechten

88 Vgl. hierzu: Theatermuseum, Wien, Nachlass Anna Bahr-Mildenburg, Karton 46 (Briefe Anna BahrMildenburg an Hermann Bahr der Jahre 1909 und 1910).

89 Vgl. dazu den Brief von Strauss an Schuch vom 15. November 1910, in dem es um Strauss' Anwesenheit in Dresden für eine Probe des Rosenkavalier ging, dessen Uraufführung am 26. Januar 1911 stattfand: „Aller Voraussicht nach werde ich am 11. Dezember Abends 7 Uhr in Dresden ankommen und kann bis 12. Dezember abends da bleiben, natürlich wenn ich in diesen 2 Tagen eine vollständige Klavierprobe des Rosencavalier anhören kann. Ich darf wohl annehmen, daß der I u. II. Akt bis dahin bereits auswendig u. d. III. Akt von Noten wenigstens so correkt gesungen werden kann, daß man mit den Sängern bereits auf den Ausdruck hin studieren kann. Sonst nämlich hat meine Anwesenheit keinen Zweck." (siehe Gabriella Hanke Knaus (Hrsg.), Richard Strauss - Ernst von Schuch: Ein Briefwechsel [Veröffentlichungen der Richard-Strauss-Gesellschaft, Bd. 16], Berlin 1999, S. 161) - Für den 16. Januar 1911 kündigte Strauss sein abermaliges Kommen an (ebd., S. 172).

90 Für den Rosenkavalier ist davon die Rede, dass Strauss mit Ausnahme der o. g. Probe die Arrangierproben Max Reinhardt, Hugo von Hofmannsthal und Alfred Roller überlassen wollte (Hanke Knaus, ebd., S. 165). 
zu sehen“. ${ }^{91}$ In Wien traf Hofmannsthal erst zehn Tage vor der Aufführung ein, Strauss noch deutlich später. Ausweislich der Briefe an Hermann Bahr kamen zwischen dem Autorenteam und Anna Bahr-Mildenburg keinerlei schriftliche oder mündliche Verabredungen zur Umsetzung der Klytämnestra zustande. ${ }^{22}$ Hieraus wird man freilich nicht schließen dürfen, dass Strauss und Hofmannsthal die gesangliche und dramatisch-gestische Umsetzung ihrer Figuren auf der Bühne gleichgültig war. Im Gegenteil ergibt sich aus dem eingangs angeführten Zitat, dass Strauss auch auf die schauspielerische Arbeit seiner Sänger allergrößten Wert legte. Vielmehr wollte er offenbar Auktorialität im Hinblick auf die Umsetzung seiner Figuren nicht in Anspruch nehmen. Es verwundert daher weder, dass Bahr-Mildenburg von Strauss keinerlei Hinweise zu der Frage bekam, was in der Partitur möglicherweise in Bezug auf die gestische Ausgestaltung zu „entdecken“ sei, da er dies seinen Künstlern nicht vorschreiben, sondern wie dies auch 1909 offensichtlich noch immer üblich war - ihrer jeweils eigenen Gestaltungskraft überlassen wollte. Es verwundert auch nicht, dass Bahr-Mildenburg die Arbeit an der Figur auf der Grundlage ihrer Notizen im Klavierauszug ganz allein leistete, und zwar so, wie sie es selbst für richtig hielt. Wie aus den zitierten Briefen an ihren Mann hervorgeht, gab es auch für sie keine bindenden Vorschriften in der Partitur hinsichtlich der Interpretation der Klytämnestra. „Körperschrift“ in der Partitur entdecken zu wollen, hielte ich daher schon aus diesem Grund für problematisch.

Und noch ein letztes theatergeschichtliches Detail sei zum Schluss angeführt: Vergleicht man die Fülle der Eintragungen im Klavierauszug Anna Bahr-Mildenburgs mit einer heutigen Aufführung (etwa mit Eva Marton als Elektra und Brigitte Fassbaender als Klytämnestra in der Wiener Staatsoper unter Leitung von Claudio Abbado aus dem Jahr 1989), kann ich mir angesichts des von Abbado angeschlagenen Tempos nicht vorstellen, wie die zahlreichen Bewegungsvorschriften der Künstlerin dort unterzubringen sein könnten. Diese sind meines Erachtens nur sinnvoll bei einem deutlich langsameren Tempo auszuführen. Dass in der Wiener Erstaufführung wohl tatsächlich ein vergleichsweise langsames Tempo gewählt worden ist, legt ein Brief Anna Bahr-Mildenburgs an ihren Ehemann vom 26. Januar 1909 nahe. In diesem berichtet sie Bahr, die Klytämnestra mit Kapellmeister Hugo Reichenberger zu studieren, doch stellte sich später heraus, dass dieser ganz andere Tempi genommen habe, als Strauss es wollte. "Wir haben sehr gelacht“, heißt es bei ihr, „weil ich den Componisten so hetzte und trieb, dass er ganz erschöpft zum Schluss war." - Strauss wollte also ein deutlich langsameres Tempo haben, als Reichenberger es zunächst einstudiert hatte. Ob dieses dann in der Aufführung tatsächlich realisiert wurde, muss natürlich dahin gestellt bleiben. Deutlich wird hieraus aber, dass die Variablen, denen eine Aufführung unterliegt, außerordentlich vielgestaltig sind. Und wenn dies schon für das genaue Tempo gilt, dann gilt dies erst recht für die gestische Ausgestaltung einer Figur, die vielfältigen historischen Einflüssen unterliegt und daher nicht in einer Partitur festgeschrieben sein kann.

91 Vgl. Willi Schuh (Hrsg.), Richard Strauss - Hugo von Hofmannsthal. Briefwechsel, München 1990, S. 52.

92 Nach meinen Feststellungen datieren die im Wiener Nachlass der Künstlerin befindlichen Briefe von Strauss sämtlich erst nach der Wiener Aufführung (vgl. Theatermuseum, Wien, Karton 27, Korrespondenz Sti bis Sz). Im Richard-Strauss-Archiv in Garmisch gibt es aus dieser Zeit ebenfalls keine Korrespondenz; die dort vorhandenen Briefe der Sängerin beschränken sich auf die 1930er Jahre (für diese Mitteilung bedanke ich mich herzlich bei Herrn Dr. Jürgen May, Richard-Strauss-Institut, GarmischPartenkirchen). 


\section{Fazit}

Der Klavierauszug Anna Bahr-Mildenburgs zur Elektra ist aus vielerlei Gründen von hohem theatergeschichtlichem Wert: Er reflektiert die fortschrittlichen Bestrebungen hinsichtlich der gestischen Ausgestaltung der Figuren, die seit der Jahrhundertwende ganz allmählich auf der Bühne Raum gewannen, und zeigt die Künstlerin als Fahnenträgerin dieser neuen Denkungsarten. Sie entsprach damit zugleich den Vorstellungen des Komponisten, der sich nicht „gewöhnliche Opernsänger“ für seine Werke wünschte, sondern - wie man heute sagen würde Sängerdarsteller.

Wissenschaftlich fast noch interessanter erscheint mir jedoch, dass mit Hilfe der Einzeichnungen Anna Bahr-Mildenburgs in ihrem Elektra-Klavierauszug die Medialität von Körper und Singstimme der Darsteller und Darstellerinnen im Musiktheater auch für die Forschung nutzbar gemacht werden kann. Diese Einzeichnungen beschreiben nämlich, wie Emotion auf der Bühne sichtbar wird. Sie verweisen damit auf die Leiblichkeit des Darstellers, die zeigt, was die Rede / die (Sing-)Stimme verschweigt bzw. nicht zeigen kann. ${ }^{93}$ Dies setzt freilich voraus, dass man man Sprache und Stimme im Sinne von Sybille Krämer und Dieter Mersch als „verkörperte Sprache“ ansieht. Die Stimme erfüllt eine performative Funktion, indem sie Geschriebenes bezeichnet und Gesprochenes zeigt. ${ }^{94}$ Zudem lässt die Stimme nicht nur die Botschaft, sondern auch den Leib des Sprechers / der Sprecherin hören; in ihr wendet sich der / die Redende dem Gegenüber zu. ${ }^{95}$ Im mimischen, gestischen und körpersprachlichen Vollzug wird nicht nur die Medialität der Sprache greifbar, sondern - durch Analogisierung des Sprechens mit einem musikalischen Geschehen ${ }^{96}$ - auch eine solche der Singstimme. Ausgehend von der Vorstellung, „dass Musik Aktion ist und daher stets den ganzen Menschen fordert "97, scheint mir, dass auf diese Weise die Begriffe „Performanz “ und „Performativität“ neu akzentuiert werden könnten, was freilich zu einer Verschiebung, wenn nicht sogar einer Revision des Austin'schen Performanzbegriffs nötigte: nicht der Sprechakt als solcher steht im Mittelpunkt des Interesses, sondern die Art und Weise des Vollzugs seines Gehalts.

Auch wenn nach dem vorstehend Ausgeführten die Partitur der Elektra nicht als Regiebuch aufgefasst werden kann und die Einzeichnungen Bahr-Mildenburgs daher nicht als „Umsetzung " des von der Musik möglicherweise Angedeuteten gesehen werden dürfen, so bieten diese Einzeichnungen dennoch eine Möglichkeit, der Musik und Text einkomponierten Performativität auf die Spur zu kommen.

93 Vgl. Krämer, „Stimme - Sprache - Schrift. Schrift“, S. 323ff.

94 Mersch, „Jenseits von Schrift“, S. 79ff.

95 Ebd., S. 86 und S. 90.

96 Vgl. Krämer, „Stimme - Sprache - Schrift“, S. 338f.

97 Monika Woitas, „Die Bühne als Partitur“, in: Erkenntnisgewinn durch Methode? Kulturwissenschaft, Genderforschung und Musikwissenschaft, hrsg. von ders. und Corinna Herr, Köln 2006, S. 239ff, Zitat S. 246. 